\title{
Discussion on the Formulation of Government Public Management Mechanism in Rural Tourism Development
}

\author{
Haoran Yang Huilan Yang* \\ College of Humanities and Social Sciences, Public Administration, Inner Mongolia Agricultural University, Hohhot 010018, Inner \\ Mongolia, China
}

\begin{abstract}
In recent years, with the continuous improvement of people's living standards, more and more people choose rural leisure tourism to relax, which temporarily helps them escape from the stress of busy work. General Secretary Xi Jinping emphasized while attending the discussion of the 19th National People's Congress of Guizhou Province that it is not only necessary to encourage the development of country farmhouses, but also shall analyze and forecast rural tourism, and develop measures in advance to ensure the sustainable development of rural tourism. As a new emerging tourism project, rural tourism has been being accepted by all kinds of people. The prosperous development of rural tourism can not only effectively promote the development of rural economy and win the battle against poverty, but also is beneficial to the overall development between urban and rural areas. However, due to a lack of policy support and adequate public management during the development of rural tourism, the development of rural tourism in many areas has shown a disorganized state. In this paper, it analyzes the formulation of the government's public management mechanism in the current rural tourism development process, which will effectively improve the quality of rural tourism development, give a full play to the government's public management functions, and ensure stable development of the rural tourism industry.

Keywords: rural tourism; government public management functions; mechanism development analysis

Author's Informarion: Haoran Yang (June 1, 1994), male, Mongolian, Ordos, Inner Mongolia, graduate student in administration. Main research area: government economics.

*Corresponding Author: Huilan Yang, College of Humanities and Social Sciences, Inner Mongolia Agricultural University, Associate Professor
\end{abstract}

DOI: $10.36012 / \mathrm{ems} . v 1 \mathrm{il} .958$

\section{Introduction}

A s people's consumption concepts and lifestyles have changed dramatically; more and more people start to pursue spiritual satisfaction. For which travel can provide people with an opportunity of learning about the different cultural environments in other regions in a short time, and obtain different shopping experiences. Through the combination of tourism activities and relevant industries, it can also further promote the economic development of the society. For which, the tourism industry has gradually become an important part of the national economy. Rural tourism is different from tourism in the old days. The rural tourism now emphasizes more of the experience returning to the natural life. Through rural tourism, urban people can also relax and enjoy the beauty of natural life in their busy works. For which, rural tourism has become accepted and recognized by more and more people. However, during the process of rural tourism development, due to the lack of government public management, it is not that ideal the effect of rural tourism development.

\section{Necessity of Constructing Public Manage- ment Mechanism for Rural Tourism Gover- nance}

With the continuous deepening of the market economy system reform in China, the market plays a leading 
role in the allocation of resources. Due to the imperfect development of the market economy system in China, it occurs often the problem of market mechanism failure. Therefore, we must give a full play to the government's public management functions in economic activities. The invisible hand of the government can effectively and scientifically promote the allocation of market resources and income distribution and then promote the stable growth of the economy.

As an emerging industry that is directly related to the masses, if rural tourism lacks government public management during its development, it will easily show malformed development in the fierce market competition. For example, in the case of the Northeast Snow Township happened earlier this year, due to the lack of government public management, it has caused a disordered local tourism market, for which the problem of arbitrary ripping off passengers was very prominent, which not only affected the development of local rural tourism, but also severely damaged consumer confidence. Besides, during the development of rural tourism, it must be equipped with certain public infrastructures, such as tourism dedicated lanes, water, and electrical infrastructure support, environmental sanitation, and relevant services related to public information. All of these supporting services are public benefits and must be achieved by government funding, otherwise, it will not be possible to achieve solely relying on the market itself.

\section{Current Existing Problems in Government Public Management in China's Development of Rural Tourism}

\subsection{Lack of Overall Planning for Rural Tourism}

In recent years, even it has a relatively prosperous development of rural tourism in various parts of the country, but due to the lack of effective overall planning for rural tourism, the problem of the sameness development of rural tourism has appeared in many regions, such a problem is shown in both projects and services. And such the same rural tourism cannot stand out in the fierce market competition and it will also limit the development of rural tourism in the future. During the process of rural tourism development, due to the low barriers to entry, many regions just started to receive tourists by adding certain services to the original agricultural foundation, which not only led to unsatisfactory tourism results, but also can easily affect the legal rights and interests of tourists themselves.

\subsection{Lack of Improved Management Mechanism}

Due to the inadequate management system during the development of rural tourism, there was no corresponding department for dealing with the disputes rising in rural tourism. Generally speaking, the management department of rural tourism involves multiple departments, such as agricultural town planning, tourism cultural relics protection, environmental protection, etc. When there are favorable resources, every department will compete to obtain favorable resources, and they will be buck-passing when there is no interest. Such a situation has reduced the management efficiency of rural tourism management. During the development of rural tourism, the situation of appointing people by favoritism and family management also limits the smooth development of rural tourism ${ }^{[2]}$.

\subsection{Lack of Scientific and Effective Marketing}

For rural tourism, most of the managers are farmers, for which they do not have a deep understanding of marketing concepts. The marketing strategies for rural tourism are still in the elementary copying mode, which cannot fully expand the effect of publicity, resulting in a small operation of rural tourism operation and lacking a certain brand building concept. Besides, some villagers lack a sense of market competition, their concepts of "waiting for business" has also led to a short development of rural tourism.

\section{Development of Government Public Man- agement Mechanism in Rural Tourism De- velopment}

\subsection{Strengthening the Policy Guiding Mechanism for Public Management of Rural Tourism}

During the development of rural tourism, the government must give full play to its support advantages to fully solve the practical rural problems. First, it must formulate relevant policies and regulations by following the actual conditions of the rural market, ensure to carry out a comprehensive planning for the overall development of rural tourism and set different themes to ensure the characteristics of rural tourism based on the different resources and location advantages of the tourism destination. Second, it shall improve the relevant laws and regulations based on studying the laws and regulations of the Land Management Law, the Rural Land Contract Law and the Tourism Management Regulations. Besides, by formulating laws on rural 
tourism operation or tourism safety management it can guarantee the effective implementation of rural laws, to fully protect the rights and interests of tourists, and create a fair and open competitive market ${ }^{[3]}$.

\subsection{Establish A Decision-Making Coordination Mechanism for Public Management of Rural Tourism}

The scientific and efficient tourism management coordination mechanism can promote the sustainable development of rural tourism. On the one hand, during the continuous development of rural tourism, it will impact local society, economy, and culture, not only because rural tourism is related to agriculture, tourism, business management, etc., but also involves folk customs and other aspects. Therefore, it is necessary to actively build an effective decision-making coordination mechanism to actively coordinate the interests of investors, operators, and residents. Also, while establishing rural public management decision-making mechanism, it shall include organizational and institutional guarantees, and clarify the rights of participation of all parties by establishing relevant organizations, and shall actively listen to the opinions of all parties during the decision-making process. So that can we find the best balance point while playing games with different parties. Through effectively regulating the decision-making behaviors, it can assure a fair and democratic public management of rural tourism, and constantly improve the entire management level. During the process of decision-making, if there is a plan that violates the decision-making, it must be corrected promptly, and shall analyze the cause of the problem to strengthen the protection of rural tourism and the sustainable development of the community economy.

\subsection{Establishing Consultation and Communication Mechanism for Public Management of Rural Tourism}

With the arrival of the modern information age of the
Internet, residents have more ways to obtain information. Therefore, while establishing the public management system for rural tourism, it shall ensure that government affairs are open and fully respect the participation rights of the society, and strengthen the management of the information of local people and further implement the obligation of reminding. Therefore, while formulating information disclosure consultation, it can publish data information through channels such as news media, press conferences, the internet, etc. and shall accept public supervision. At the same time, it is also necessary to do well in information services. For example, it can upload the latest tourist products, activities, and price changes on the internet. It can also provide tourists with information services such as transportation, accommodation, weather, and catering, and carry out an online booking and other related services.

\section{Conclusion}

Through the full analysis of the current existing problems and shortcomings in the development of the government's public management mechanism for the development of rural tourism, it can effectively put forward the relevant mechanism development methods, strengthen the development of rural tourism, further build the rural tourism culture brand and promote the sustainable and healthy development of rural tourism.

\section{References:}

[1] Ping Du. Exploring the Development Path of Rural Tourism Cultural Resources from the Perspective of Public Management [J]. Journal of Kaifeng Institute of Education, 2018, 38 (04): 272-274.

[2] Yanan Xu. Study on Government Responsibility in the Development of Rural Tourism in Dala Banner, Inner Mongolia [D]. Inner Mongolia University, 2017.

[3] Bin Hu. Study on government functions in the development of rural tourism characteristic towns [D]. Jiangxi University of Finance and Economics, 2017. 